\title{
Warrant Price Range Adjustment Based on Investor Sentiment
}

\author{
Xianming Fang \\ School of Business, Nanjing University, Nanjing, China. \\ Email: fxmfxm@nju.edu.cn

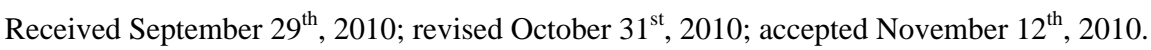

\begin{abstract}
The warrant price fluctuated in a range based on the arbitrage-free hypothesis. However, in the actual transaction, the warrant price will deviate the price range because of the investor sentiment, sometimes the deviation is too far that the actual price breaks the lower limit based on the arbitrage-free hypothesis, which make the market some arbitrage opportunities. The buyers' strength and the sellers' strength are the concentrated expression of the investor sentiment. According to the buyers' strength and the sellers' strength, a warrant price modification factor has been built with investor sentiment by function transformation. The new function adjusts the theoretical price range and identifies the arbitrage opportunities of the warrant market. The empirical test on Baotou Steel warrants shows that, after the adjustment, only a few the actual price deviates from the adjustment price range and the correction is better. So, when the warrant price trend is analyzed, the impact of the investor sentiment should be taken into account.
\end{abstract}

Keywords: Warrant, Buyers’ Strength and Sellers’ Strength, Investor Sentiment, Price Adjustment

\section{Introduction}

In fact, warrant is a kind of option, and the pricing of option is also fitted with the warrant. If the market is arbitrage-free and no transaction cost, the price of option fluctuates in a range. However, the prerequisites of the price range of warrant are difficult to exist for a long time in the actual transaction market. So, the real warrant price range is difference. Especially, the low transaction cost, high level rate, and the flexible transaction mechanism of $\mathrm{T}+0$ make the warrant more popular than underlying financial instruments, and more susceptible to the investor sentiment. In the real transaction process, the price of warrant has high volatility, sometimes breaks the theoretical range. In consideration of this situation, it's important and significative to find a real warrant price range which embodies the investor sentiment by an modification factor.

\section{Review of the Literatures}

There are plenty of pricing and price range study on the options, which can also be applied to the warrants. The prevailing view is that, the warrant price is decided by the underlying stock price and there is a theoretical price range in the transaction process in an arbitrage-free market. According to the traditional Black-Scholes Option
Pricing Formula, the price of the underlying asset is exogenous and subject to the Geometric Brown Process, and the warrant can be replicated by its underlying stock and a fixed income security. So the underlying stock price is the determinant of the theoretical warrant price. Accordingly, the actual price of the warrant will fluctuate around the theoretical price which is decided by the underlying stock price. Detemple and Selden [1] estimates the co-relationship between the warrant market and the equity market via the aspect of discrete property of the actual dealing behavior. They pointed that in the incomplete market, the prices of warrants and their underlying stock could affect each other. Using the Noisy Rational Anticipation Model, Back [2], Brennan and Cao [3], and Cherian and Jarrow [4] drew the same conclusion.

Although many papers declare that the underlying stock price is the base of the warrant price, the investor sentiment does have some influence on the formation of warrant price. Sometimes, the investor sentiment can lead the transaction price deviating from the theoretical price range. Currently, there are a few papers about the influence of investor sentiment to the warrant price. De Long, Shleifer, Summers, Waldmann [5] constructed DSSW asset pricing model based on the influence of the unpredictability of irrational investor sentiment. They figured out that the investor sen- 
timent is a systematic influence factor of the equilibrium asset price. Barberis, shleifer and Vishny [6] explains the formation of sentiment and its influence to stock price according to the cognitive bias of the investors. They built the investor sentiment model about the belief formation, which is the BSV model. Daniel, Hirshlei, subrahmanyam [7] established and developed the DHS model to describe the investor behavior based on belief. The HS model, developed by Hong and Stein [8], described a mutual reaction system of two investor groups with bounded rationality. This model explained the market momentum and some other phenomena. Both the BSV model and the DHS model admit that the pessimism and optimism of the investors will lead the asset price away from its fundamentals, while the HS model explains this phenomenon in the aspect of the mutual reaction of the investors with different anticipation. These literatures are the theoretical fundamentals of the relationship between the unexpected investor sentiment and the asset return. The later work is mainly about two aspects, one is to choose proper index to evaluate the investor sentiment. For example, A. Bandopadhyaya, A. L. Jones [9], M. Burghardt, M. Czink, R. Riordan [10]. The other is to measure the influence of the investor sentiment to asset price. For example, Fisher, Statman [11], W. Antweiler, M. Frank [12], P. Tetlock [13].

With the development of the warrant market in China, the warrant price formation , the warrant price range and the influence of investor sentiment to asset price also cause the attention of the academia in China. Mingqi Jin [14] analyzed the correlation of the warrant and its underlying stock price, and concluded that, because of the different trading system, the scarcity of warrant supply and the restriction of the investor's knowledge, the warrant price is irrelated to the underlying stock price. Haozhong Sun [15] compared the warrant price calculated by Black-Scholes model and the actual price of the Baoshan Steel European call warrant, he concluded that the warrant is highly over-valued. The inconsistency of the actual price and the theoretical price of the warrant will increase the speculation and volatility of the warrant market. There are also some papers in the researches of the influence of investor sentiment to asset price. Yong Fang, Shaotang Sun used the investor expectation of future market as the proxy variable of the investor sentiment. Their results show that the investors in China are influenced by the history of the market performance and have systematic cognitive bias, so they do not have rational anticipation according to the new information. Xiaoxiao Li, Chunpeng Yang, Wei Jiang [16] built an asset pricing model based on investor sentiment accord-

${ }^{1}$ The differences of warrant and stock option are only lies in the issuer, transaction market, and some other aspects in the transaction system. But they are basically the same in the pricing mechanism. ing to DHS framework. Their model explained the overreaction and over-volatility of the stock market. They believe that the investor sentiment has reverse effect to the long term market return, and the irrational investor will increase the volatility of the short-term asset price. Yanran Wu and Liyan Han [17] expanded DSSW by investor sentiment theory to explain and test some strange phenomena of the stock market.

It can be concluded from that, the existent literatures, under the risk natural and arbitrage-free condition, the warrant price is decided by its underlying stock price, and has a definite lower and upper limits. However, in the real transaction market, the warrant price is affected by the investor sentiment. Because there are few literatures analyzed the warrant price by investor sentiment, this paper constructs an investor sentiment factor, according to the buyers' strength and the sellers' strength, to modify the warrant price range.

\section{Analytical Framework}

Given the arbitrage-free assumption, for a call warrant and a put warrant with the same underlying stock, let $t$ denote the time. The two warrants are with the same expiration date $\mathrm{T}$ and the same exercise ratio 1:1. The call warrant exercise price is $K_{c}$, and the put warrant exercise price is $K_{p}$. The underlying stock price is $S_{t}$. The theoretical price of the call warrant is $C_{t}^{*}$, and the theoretical price of the put warrant is $P_{t}^{*} . r(r>0)$ denotes the risk-free interest rate. Then, the upper and lower boundaries of call warrant and put warrant price and the spread of the theoretical price of call warrant and put warrant can be analyzed in the following framework.

\subsection{The Theoretical Warrant Price Range in an Arbitrage-Free Market ${ }^{1}$}

For the European call warrant, when $C_{t}^{*}>S_{t}$, this provides the investor an arbitrage opportunity by selling out call warrant and buying in equivalent amounts of underlying stock, which means that the call warrant is overvalued. When $S_{t}-X e^{-r(T-t)}>C_{t}^{*}$, it means that the investors are pessimistic on the warrant, and the warrant price is undervalued. The investors can obtain excessive risk-free return through buying warrant and selling out underlying stocks and lending $X e^{-r(T-t)}$ cash. The above two situation are both contradict with the arbitrage-free assumption. So the European call warrant price should be in the price range in its duration,

$$
\left(S_{t}-K_{c} e^{-r(T-t)}\right)^{+}<C_{t}^{*}<S_{t}, \quad t \in[0, T)
$$

Expression (1) is about the upper and lower boundaries of the European call warrant price in the duration. If the actual price breaks the boundaries, the investor can 
construct an arbitrage portfolio by the warrant and its underlying stock.

On the other side, the European put warrant price should be in the price range below in its duration ${ }^{2}$,

$$
\left(K_{p} e^{-r(T-t)}-S_{t}\right)<P_{t}^{*}<K_{p} e^{-r(T-t)}
$$

Expression (2) is about the upper and lower boundaries of the European put warrant price in the duration.

Let $D_{t}^{*}=C_{t}^{*}-P_{t}^{*}$ denotes the difference of the call warrant price and the put warrant price. It can be concluded from the expression (1) and expression (2) that,

$$
\left(S_{t}-K_{c} e^{-r(T-t)}\right)^{+}-K_{p} e^{-r(T-t)}<D_{t}^{*}<S_{t}-\left(K_{p} e^{-r(T-t)}-S_{t}\right)^{+}
$$

Theoretically, there is a range for the warrant price. But in the actual transaction, the warrant price would deviate from the theoretical price and break the boundaries in the expression $(1,2)$ or $(3)$ with the influence of the investor sentiment. So, it is necessary to modify the upper and lower boundaries calculated methods by the investor sentiment modification factor.

\subsection{The Actual Price Range of Warrant}

Figure 1 is about the relationship of the theoretical price range under the arbitrage-free assumption and the actual price range of the warrant in the real market.

Figure 1 shows that, the actual price range is inconsistent with the theoretical price range calculated by the arbitrage-free assumption. The upper boundary of the actual price range is higher than the theoretical price upper boundary in zone $\mathrm{B}$, while in zone $\mathrm{C}$, the lower boundary of the actual price range is lower than the theoretical price lower boundary. The fundamental of this phenomenon is that the investor sentiment affects the actual transaction price, making the price of the warrant deviate from its theoretical price and more over, breaks the arbitrage-free price range.

For the call warrant, its actual price can be divided into the theoretical price $C_{t}^{*}$ and $\Delta C_{t}^{*}$, the bias caused by the investor sentiment. Let $\rho_{t}^{c}$ denotes the modification factor, and $\Delta C_{t}^{*}=\rho_{t}^{c} \cdot C_{t}^{*}$. Then the relationship of the actual price and the theoretical price $C_{t}^{*}$ is $C_{t}=C_{t}^{*}\left(1+\rho_{t}^{c}\right)$, that is,

\footnotetext{
${ }^{2}$ When $P_{t}^{*}>X e^{-r(T-t)}$, the investors can obtain extra risk-free return by selling out put warrant and lending out $X e^{-r(T-t)}$ cash; when $X e^{-r(T-t)}-S_{t}>P_{t}^{*}$, the investors can obtain extra risk-free return by buying put warrant, borrowing $X e^{-r(T-t)}$ cash, and buying underlying stock. In this situation, the call warrant is undervalued. In both of above situation, there is arbitrage space in the put warrant market. The investors can arbitrage by constructing portfolios with the put warrant and its underlying stock.
}

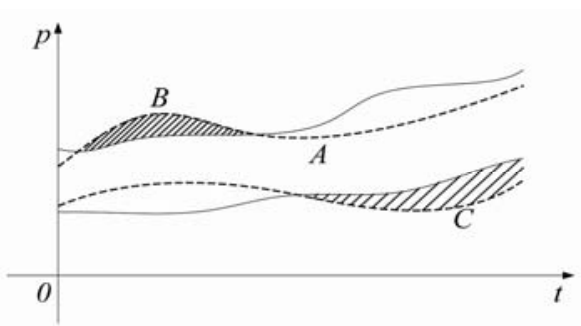

Figure 1. The actual price range and the theoretical price range.

$$
C_{t}^{*}=C_{t} /\left(1+\rho_{t}^{c}\right)
$$

According to expression (1), the actual price range of call warrant is,

$$
\left(1+\rho_{t}^{c}\right)\left(S_{t}-K_{c} e^{-r(T-t)}\right)^{+}<C_{t}<\left(1+\rho_{t}^{c}\right) S_{t}
$$

For the put warrant, the modification factor is $\rho_{t}^{D}$. According to expression (2), the actual price range of the put warrant is,

$$
\left(1+\rho_{t}^{p}\right)\left(K_{p} e^{-r(T-t)}-S_{t}\right)^{+}<P_{t}<\left(1+\rho_{t}^{p}\right) K_{p} e^{-r(T-t)}
$$

For the price difference between the call warrant price and the put warrant price, according to expression (3), $D_{t}$ is,

$$
\begin{aligned}
& \left(1+\rho_{t}^{D}\right)\left[\left(S_{t}-K_{c} e^{-r(T-t)}\right)^{+}-K_{p} e^{-r(T-t)}\right]<D_{t} \\
& <\left(1+\rho_{t}^{D}\right)\left[S_{t}-\left(K_{p} e^{-r(T-t)}-S_{t}\right)^{+}\right]
\end{aligned}
$$

where $\rho_{t}^{D}$ denotes the modification factor.

\subsection{Identifying the Modification Factor}

In the security market, if the buyers' strength stronger than the sellers' strength, the asset price shall rise; and vice versa. Therefore, it's reasonable to construct modification factor by the contrast of the buyers' strength and the sellers' strength. Namely, the investor sentiment can be expressed by the strength of the buyer and the seller. But in this process, the marginal effect diminishes. When the buyers' strength and the sellers' strength deviate from the equilibrium point, at the beginning, the marginal effect to the asset price is the strongest. The marginal effect diminishes with the deviation increasing. Diminishing marginal effect is shown in Figure 2.

Figure 2 shows how the buyers' strength and the sellers' strength influence the asset price when they break the balance point. The influence will not increase without limits. Because the asset price is internally decided by the value of the asset and the marginal effect diminishes with the increasing of the deviation degree. Hence, there 


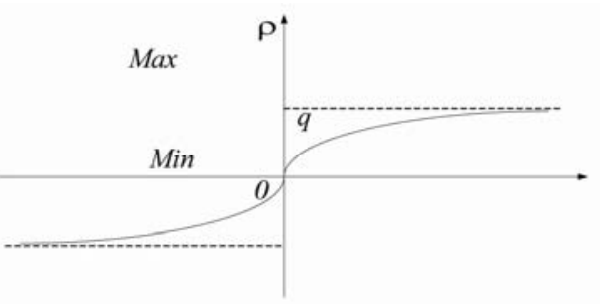

Figure 2. Diminishing marginal effects.

is a positive and a negative maximum value to describe the effects.

a) the modification factor for the call warrant and the put warrant

The modification factor should be a function of the ratio of the buying $q_{b}$ and the selling $q_{s}$. There are two kinds of functions having the similar images as Figure 2. One is the exponential function, ${ }^{3}$ the other is arc tangent function. Therefore, there may be two kinds of modify factors as below.

Exponential function form,

$$
\rho= \begin{cases}\left(\frac{q_{b}}{q_{s}}-1\right)^{\alpha} & q_{b} \geq q_{s} \\ -\left(\frac{q_{s}}{q_{b}}-1\right)^{\alpha} & q_{b}<q_{s}\end{cases}
$$

Arc tangent function form ${ }^{4}$,

$$
\rho= \begin{cases}\frac{2}{\pi} a \tan \left(\frac{q_{b}}{q_{s}}-1\right) & q_{b} \geq q_{s} \\ -\frac{2}{\pi} a \tan \left(\frac{q_{s}}{q_{b}}-1\right) & q_{b}<q_{s}\end{cases}
$$

In order to adjusting the function to fit the transaction

\footnotetext{
${ }^{3}$ Although there is no upper and lower boundary in exponential function when choosing proper value of parameter $\alpha$, the function graph is very similar to Figure 2. And in most situation, the variable $q_{b} / q_{s}$ or $q_{s} / q_{b}$ is not infinite, so the exponential function could be one form of modification factor.

${ }^{4}$ The range of arc tangent function is $[-\pi / 2, \pi / 2]$. Considering that the warrant price is internally determined by its value, the absolute value of the modification factor should be less than 1 . So, the arc tangent expression should multiple $2 / \pi$.

${ }^{5}$ In the expression of $q(t), q_{1}^{c}(t)+q_{2}^{p}(t)$ is the sum volume of the buying call warrant and the selling the put warrant, while $q_{2}^{c}(t)+q_{1}^{p}(t)$ is sum volume of the selling the call warrant and the buying the put warrant.

${ }^{6}$ According to the definition of $q(t)$, the larger $|q(t)|$ express that the sum volume of the call warrant buying and the put warrant selling is more different with the sum volume of the call warrant selling and the put warrant buying. The investors will emphasis on the internal value of the call warrant and put warrant more in this condition.

${ }^{7} A=q_{1}^{c}(t)+q_{2}^{p}(t), B=q_{2}^{c}(t)+q_{1}^{p}(t)$
}

price, parameter $\gamma$ and $k$ are added into the expression $(8,9)$. Then the two forms of modify factor could be,

$$
\begin{aligned}
& \rho=\left\{\begin{array}{l}
\left(\gamma \cdot \frac{q_{b}}{q_{s}}-1\right)^{\alpha} / k \quad q_{b} \geq q_{s} \\
-\left(\gamma \cdot \frac{q_{s}}{q_{b}}-1\right)^{\alpha} / k \quad q_{b}<q_{s}
\end{array}\right. \\
& \rho=\left\{\begin{array}{l}
\frac{2}{\pi} a \tan \left(\gamma \cdot \frac{q_{b}}{q_{s}}-1\right) / k \quad q_{b} \geq q_{s} \\
-\frac{2}{\pi} a \tan \left(\gamma \cdot \frac{q_{s}}{q_{b}}-1\right) / k \quad q_{b}<q_{s}
\end{array}\right.
\end{aligned}
$$

b) the modify factor of the difference of the call warrant price and the put warrant price with the same underlying asset

The price of the call warrant and the put warrant with the same underlying asset is influenced by four kinds of market strength. Namely, the buying and selling strength of the call warrant, and the buying and selling strength of the put warrant. Let $q_{1}^{c}(t), q_{2}^{c}(t)$ denote volume of buying and selling the call warrants at time $t$, and $q_{1}^{p}(t), q_{2}^{p}(t)$ denote volume of buying and selling the put warrants at time $t$. When volume of buying call warrant and selling put warrant is more than the volume of selling call warrant and buying put warrant, the modification factor of the difference between the call warrant price and the put warrant price causing by the investor sentiment can be represented by

$$
q(t)=\left[q_{1}^{c}(t)+q_{2}^{p}(t)\right] /\left[q_{2}^{c}(t)+q_{1}^{p}(t)\right]-1 .^{5}
$$

And in the opposite situation, the modification factor of the difference between the call warrant price and the put warrant price causing by the investor sentiment can be represented by

$$
q(t)=\left[q_{2}^{c}(t)+q_{1}^{p}(t)\right] /\left[q_{1}^{c}(t)+q_{2}^{p}(t)\right]-1 \text {. The mar- }
$$
ginal effect of $q(t)$ decreases with the growing of the absolute value of $q(t){ }^{6}$ The difference of the call warrant price and put warrant price would be positive or negative. When the theoretical price difference is positive, the exponential function form and the arc tangent function form of modify factor would be,

$$
\rho_{t}^{D}=\left\{\begin{array}{cc}
{[A / B-1]^{\alpha}} & A \geq B \\
-[B / A-1]^{\alpha}, & A<B
\end{array}\right.
$$

And

$$
\rho_{t}^{D}= \begin{cases}\frac{2}{\pi} a \tan (A / B-1), & A \geq B \\ -\frac{2}{\pi} a \tan (B / A-1), & A<B\end{cases}
$$


When the price difference of call warrant price and put warrant price is negative, the plus signs in front of the modify factor expressions above should be replaced by the minus signs. At the same time, the minus signs should be replaced by plus signs.

\section{Empirical Study on China's Warrant Market}

In China's capital market, several warrants have been listed in the warrant market, such as Bao Steel JTB1, Vanke HRP1, Steel Vanadium PGP1, WISCO JTB1, WISCO JTP1, etc. At the beginning of China's warrant market, these warrant prices had been greatly disturbed by the irrational speculation. The duration of BAOGANG JTB1 \&JTP1 started from March 31, 2006 and ended in March 30, 2007, which avoided the price influence factors mentioned above. This makes BAOGANG warrant a good sample to study the warrant price in China. So in this paper takes the price data of the BAOGANG call warrant (BAOGANG JTB1) \& BAOGANG put warrant (BAOGANG JTP1) in their whole duration as the sample.

\subsection{Data Sources and Statistical Description}

The data required in the empirical test is collected from the Wind Info database. The price data of BAOGANG JTB1 \&JTP1 is collected every half-hour in all trading day of their duration (from March 31, 2006 to March 30, 2007). After excluding the trading days with stock trading suspension and the trading days with abnormal stock price fluctuation caused by information asymmetric when the company announced some important matters, there is 1104 data in the sample. Figure $\mathbf{1}$ shows the trend of BAOGANG JTB1 price and BAOGANG stock price.

In Figure 3, the BAOGANG JTB1 price and the BAOGANG stock price have almost the same trend. But the price of BAOGANG JTB1 also has its own character. Generally, the price movement of JTB1 could be divided into three phases. The first phase is comprised by the first two hundred sample points. In this period, the BAOGANG warrant had just been listed, and the price of BAOGANG stock and BAOGANG JTB1 exhibited high volatility; the second phase covers the 201th sample point to the 800th sample point. In this period, the movement of the BAOGANG stock price and the price of BAOGANG JTB1 is relatively smooth; the third phase contains all the rest sample points. In this phase, the BAOGANG stock price went up rapidly, and fluctuated

\footnotetext{
${ }^{8}$ S, CALL in Figure 3 denote the price of the BAOGANG stock price and the price of BAOGANG JTB1 respectively.

${ }^{9} \mathrm{CD}$, CU, and CALL in Figure $\mathbf{4}$ denote the lower boundary and the upper boundary of theoretical price range, the actual price of BAOGANG JTB1 respectively.
}

violently in the last period. The price of JTB1has the same movement as the stock price of BAOGANG JTB1.

The theoretical price of warrant and the upper boundary and lower boundary of BAOGANG JTB1 according to expression (1) is shown in Figure 4.

According to Figure 4, in the first 200 sample points, most points of the actual price of BAOGANG JTB1 are fluctuating in its theoretical price range. But generally, the price is more close to the lower boundary of the theoretical price range, and several sample points are even lower than the arbitrage-free lower boundaries. From the 201th sample points to the 800th sample points, the price of BAOGANG JTB1 is in the theoretical price range, but still closer to the lower boundaries than the upper boundaries. However, after the 800th sample points, the actual transaction price breaks the lower boundaries of the theoretical arbitrage-free price range at many sample points.

In the duration of the BAOGANG warrant, the comparison of the buying strength of JTB1 and the selling strength is shown in Figure 5.

Figure 5 shows that, although at most sample points, the buying and selling are almost the same. But there are also some sample points that the buying and selling has significant differences. These differences will impact the volatility of the BAOGANG JTB1. So, it is necessary to adjust the theoretical price range of the warrant.

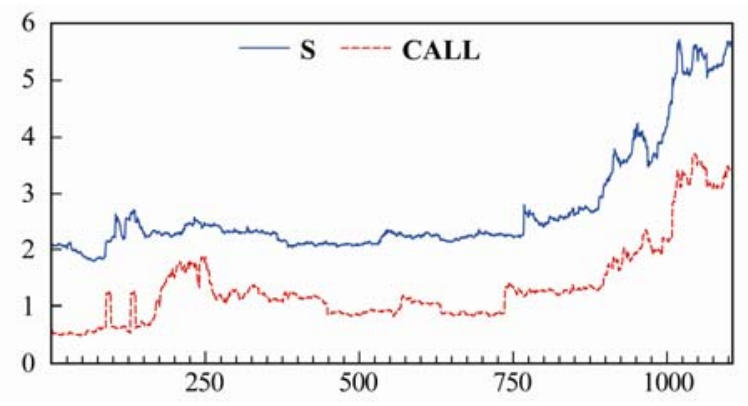

Figure 3. BAOGANG JTB1 price and BAOGANG stock price (2006.3.31 2007.3.31). ${ }^{8}$

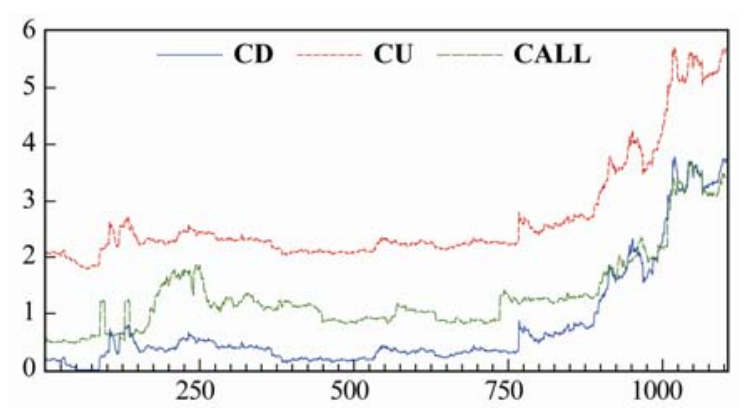

Figure 4. the theoretical warrant price range and actual price of JTB1. ${ }^{9}$ 
After the adjustment by adding in the exponential function form modify factor of expression (8), the BAOGANG JTB1 price range is painting in Figure 6.

Figure 6 shows that, after the adjustment of the exponential function form modification factor, in the first 200 sample points, almost all points are between the modified price range. In the 201th sample points to the 800th sample points, the actual price of BAOGANG JTB1 is in the middle of the modified price range. After the 800th sample point, most points are in the modified price range, and the number of the sample points that break the range is much less than that in the Figure 4.

The modified price range of BAOGANG JTB1 by the arc tangent form modify factor in expression (9) is shown in Figure 7.

In Figure 7, after the adjustment of the arc tangent function form modification factor, all of the first 800 sample points are in the modified price range, and the actual price is closer to the upper boundary of the modified price range. It means that the modification makes the price range generally move downward. Like the exponential function form modification factor situation, most sample points are in the modified price range and only a few breaks the lower boundary. But when using the arc tangent function modification factor, because of the great disparity of the buying strength and the selling strength, the modified price range is not smooth. And the disparity in the buying strength and selling strength results in some mutations in the modified price range.

Comparing Figure 6 and Figure 7, it can be concluded that both modification factors can adjust the BAOGANG JTB1 price range. And the modification is effective. But there are still a few sample points breaking the modified price boundaries. This problem can also be settled by changing the parameter $\gamma$ and $k$. Because the different value of $\gamma$ and $k$ will lead to different price range modification effects. But this will bring a new problem. Too much emphasis on the buying strength and selling strength will lead to sharp mutation on price range. Therefore, different parameters should be applied in different phases. But it remains to discuss on how to choose proper parameter value. And it is worth to notice that the arc tangent modification factor changes the price range more than the exponential modification factor does with the same $\gamma$ and $k$ value.

The result, studying on BAOGANG JTP1, shows that

\footnotetext{
${ }^{10} \mathrm{CB}$, CS in Figure 5 represents the buying and selling of BAOGANG JTB1 on each sample points.

${ }^{11} \mathrm{CD}$, CU in Figure 6 denotes the lower price boundary and the upper price boundary of the price range after the adjustment of the exponential function modification factor.

${ }^{12} \mathrm{CD}$, CU in Figure 7 denotes the lower price boundary and the upper price boundary of the price range after the adjustment of the arc tangent function modification factor.
}

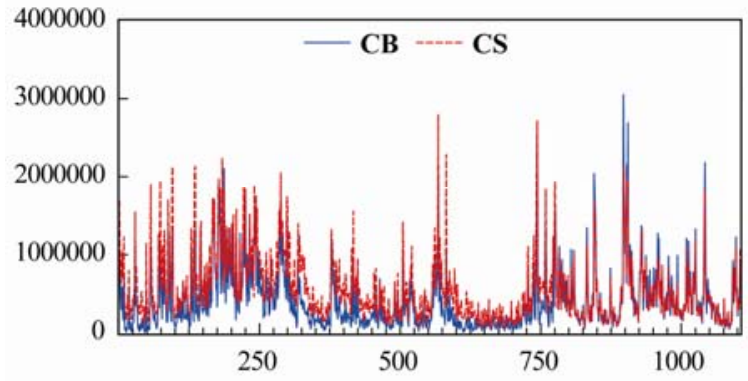

Figure 5. The comparison of the buying and selling strength of JTB1（2006.3.31 2007.3.31） ${ }^{10}$.

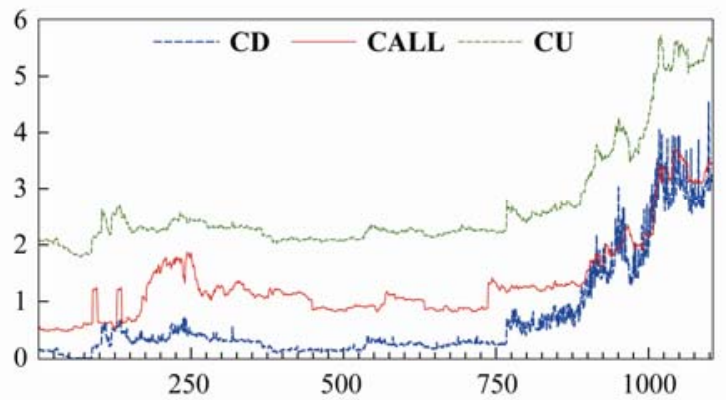

Figure 6. The price range of JTB1 after the exponential function form $(\gamma=1, k=1)$. $^{11}$

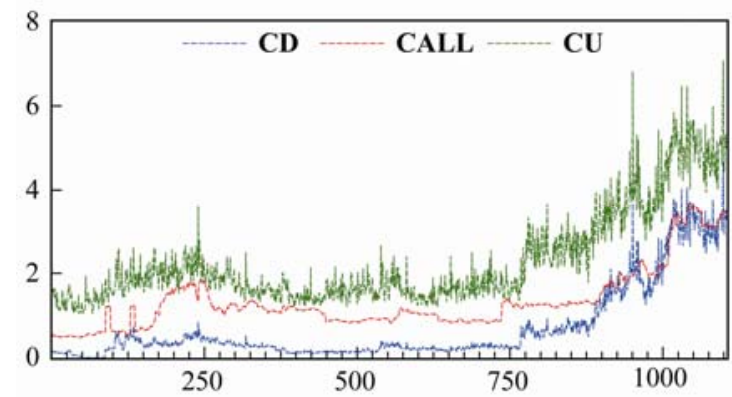

Figure 7. The modified price range of JTB1 by the arc tangent $(\gamma=1, k=1) \cdot{ }^{12}$

most sample points of JTP1 are close to the lower boundary of the theoretical price range. After the modification, the transaction price is almost in the middle of the modified price range. The price difference study of BAOGANG JTB1 and BAOGANG JTP1 also gets similar conclusions as the study of the BAOGANG JTB1.

\section{Conclusions}

Just like the options, the warrants price has to maintain in some range to keep away from arbitrage. However, in the actual transaction, the investor sentiment will lead the warrant price and the price difference of the call warrant price and put warrant price deviating from the theoretical 
price range, and sometimes breaking the upper and lower boundaries of the price range. So, it is necessary to modify the price range to identify the real arbitrage space. For this reason, this paper constructs a theoretical analysis framework, and study the BAOGANG stock price and its warrants. The research shows that,

1) Under the arbitrage-free assumption, the warrant price will fluctuated in a theoretical price range. But because of the investor sentiment, the actual price of warrants will break the range. Since the comparison of buyers' strength and sellers' strength gives expression to the investor's interests to the warrants, this paper construct modification factor by investor sentiment to adjust the price range of the warrants.

2) The marginal effect of the influence of investor sentiment diminishes. In the balance condition, the investor sentiment has little influence on the warrant price. Once the buyers' strength and the sellers' strength are not equal, they will influence the warrant price. This influence increases with the deviation degree, but the growth rate decreases. That means the influence will not be boundless. Therefore, the exponential function and arc tangent function can be used to construct the modification factor.

3) The empirical test based on the entire duration of the BAOGANG warrants shows that both modification factors can adjust the theoretical price range effectively. Further study shows that, the modification effects vary with different parameter value. And the arc tangent modification factor changes the price range more than the exponential modification factor does with the same parameter value.

\section{REFERENCES}

[1] M. Q. Jin, "The Rationality Analysis of Warrant Price in China,” Times Finance, Vol. 19, No. 4, 2006, pp. 36-37.

[2] H. Z. Sun, "The Call Warrant Price Analysis: An Example for BAOSTEEL Warrant,” South China Finance, Vol. 11, No. 1, 2006, pp. 55-57.

[3] X. X. Li, C. P. Yang and W. Jiang, "Behavioral Asset Pricing Model Based on Investor Sentiment," Journal of Qingdao University (Natural Science Edition)," Vol. 21, No. 4, 2008, pp. 95-98.

[4] Y. R. Wu and L. Y. Han, "Explanations of Strange Financial Phenomena Based on the Investor Sentiment," Journal of Shanxi Finance and Economics University, Vol. 31, No. 2, 2009, pp. 95-100.
[5] Detemple amd Selden, “A General Equilibrium Analysis of Option and Stock Market Interactions," International Economic Review, Vol. 10, No. 32, 1991, pp. 279-303.

[6] K. Back, "Asymmetric Information and Options," Reviews of Financial Studies, Vol. 6, No. 3, 1993, pp. 435472.

[7] J. Michael and H. H. Brennan, "Information, Trade, and Derivative Securities," Review of Financial Studies, No. 9, 1996, pp. 163-208.

[8] J. Cherian and R. Jarrow, "Options Markets, Self-fulfilling Prophecies and Implied Volatilities," Review of Derivatives Research, Vol. 10, No. 2, 1998, pp. 5-37.

[9] J. B. DeLong, A. Shleifer, L. H. Summers and R. J. Waldmann, "Noise Trader Risk in Financial Markets," Journal of Political Economy, Vol. 98, No. 4, 1990, pp. 703-738.

[10] Barberis, A. Shleifer and R. Vishny, “A Model of Investor Sentiment,” Journal of Financial Economics, Vol. 49, No. 3, 1998, pp. 307-343.

[11] K. Daniel, D. Hirshleifer and A. Subrahmanyam, "Investor Psychology and Security Market Under- and Overreactions," Journal of Finance, Vol. 53, No. 6, 1998, pp. 1839-1885.

[12] H. Hong and J. C. Stein, “A Unified Theory of Underreaction, Momentum Trading and Overreaction in Asset Markets,” Journal of Finance, Vol. 54, No. 6, 1999, pp. 2143-2184.

[13] K. L. Fisher and M. Statman, "Consumer Confidence and Stock Returns," Journal of Portfolio Management, Vol. 30, No. 1, 2003, pp. 115-128.

[14] W. Antweiler and M. Frank, "Is All That Talk Just Noise? The Information Content of Internet Stock Message Boards,” The Journal of Finance, Vol. 59, No. 3, 2004, pp. 1259-1294.

[15] P. Tetlock, "Giving Content to Investor Sentiment: The Role of Media in the Stock Market," The Journal of Finance, Vol. 62, No. 3, 2007, pp. 1139-1168.

[16] M. Burghardt, M. Czink and R. Riordan, "Retail Investor Sentiment and the Stock Market," Working Paper, 29 February 2008.

[17] A. Bandopadhyaya and A. L. Jones, "Measuring Investor Sentiment in Equity Markets," Working Paper, February 2005.

[18] M. Bhattacharya, "Price Changes of Related Securities: The Case of Call Options and Stocks," Journat of Financial and Quantitative Analysis, No. 22, 1987, pp. 1-15.

[19] P. Christophe, "Testing the Monotonicity Property of Option Prices," The Journal of Derivatives, 2006, pp. 61-76. 